\title{
Facile Synthesis of Au Nanoparticles@Reduced Graphene Oxide Nanocomposition-Modified Electrode for Simultaneous Determination of Copper and Mercury Ions
}

\author{
Youzhi Yao \\ Wuhu Institute of Technology, Wuhu 241003, China. \\ E-mail: yaoyz@,whit.edu.cn
}

doi: $10.20964 / 2019.04 .06$

Received: 28 October 2018 / Accepted: 26 January 2019 / Published: 10 March 2019

\begin{abstract}
A highly efficient electrochemical sensor consisted by gold nanoparticles (Au NPs) loaded on reduced graphene oxide (RGO) nanosheets for $\mathrm{Cu}^{2+}$ and $\mathrm{Hg}^{2+}$ was developed. The electrochemical performances of as-prepared bare glassy carbon electrode (GCE), RGO/GCE, Au NPs@RGO/GCE were characterized by cyclic voltammetry (CV) and differential pulse voltammetry (DPV), respectively. The Au NPs@RGO/GCE exhibited an excellent sensitivity toward $\mathrm{Cu}^{2+}$ and $\mathrm{Hg}^{2+}$. The results revealed that the detection limit of $\mathrm{Cu}^{2+}$ was $0.0015 \mu \mathrm{M}$ and $\mathrm{Hg}^{2+}$ was $0.02 \mu \mathrm{M}(\mathrm{S} / \mathrm{N}=3)$. In addition, the $\mathrm{Au}$ NPs@RGO nanocomposite modified electrode was optimized and applied for practical water sample analysis with a satisfactory outcome. The electrochemical sensor based on Au NPs@RGO would be expected to expand the application field of heavy metal detection.
\end{abstract}

Keywords: Au nanoparticles, reduced graphene oxide, simultaneous determination, electrochemical sensor.

\section{$\underline{\text { FULL TEXT }}$}

(C) 2019 The Authors. Published by ESG (www.electrochemsci.org). This article is an open access article distributed under the terms and conditions of the Creative Commons Attribution license (http://creativecommons.org/licenses/by/4.0/). 